FACULTY OF ECONOMICS AND APPLIED ECONOMIC SCIENCES

CENTER FOR ECONOMIC STUDIES

ENERGY, TRANSPORT \& ENVIRONMENT

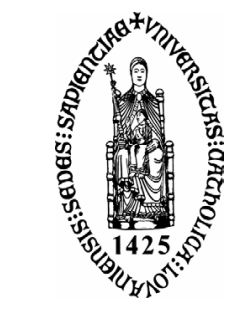

KATHOLIEKE UNIVERSITEIT LEUVEN

WORKING PAPER SERIES

$n^{\circ}$ 2005-01

\title{
The potential impact of cross-ownership in transmission: \\ An application to the Belgian electricity market
}

\section{G. Pepermans (K.U.Leuven - CES - Energieinstituut) \\ B. Willems (K.U.Leuven - CES - Energieinstituut)}

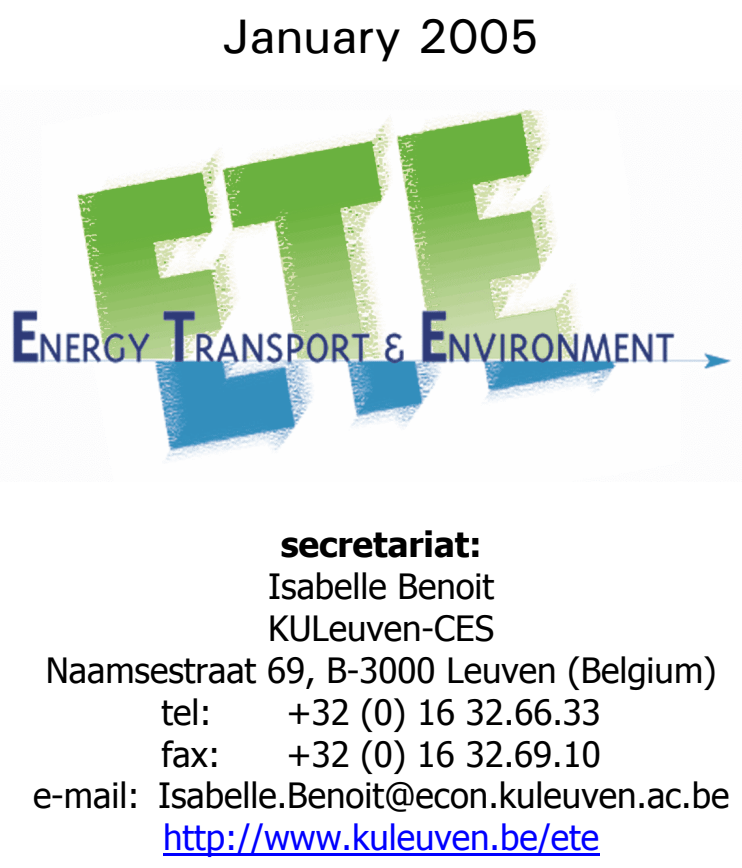




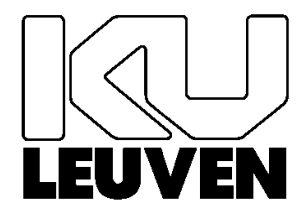

KATHOLIEKE UNIVERSITEIT

\title{
The potential impact of cross-ownership in transmission: An application to the Belgian electricity market
}

\author{
Guido Pepermans $^{\dagger}$ and Bert Willems ${ }^{\ddagger}$
}

3 January 2005

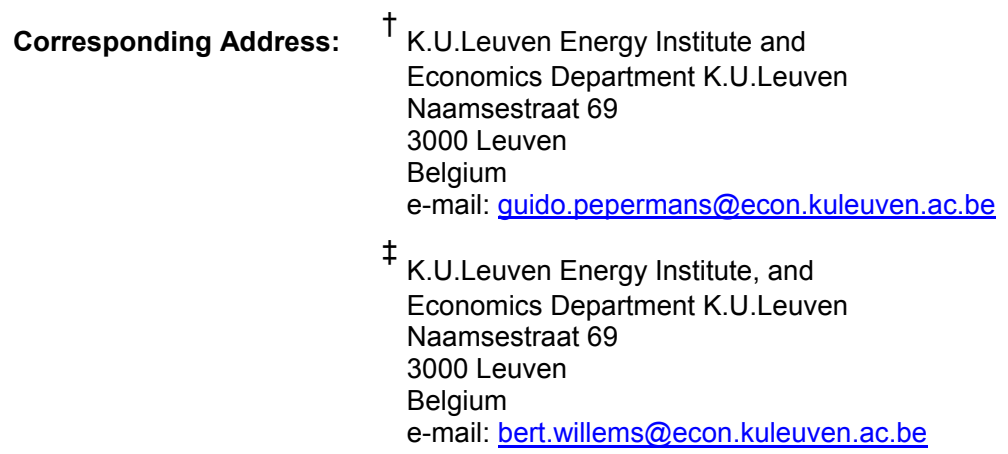




\begin{abstract}
This paper looks at the potential effect of partial ownership on the generation and the transmission sector of electricity markets. Ideally, in liberalized electricity markets, transmission is separated form generation. The transmission sector is a natural monopoly operated by a regulated transmission firm, while the generation sector is open for competition. This paper assumes that the transmission firm is not very well regulated and behaves strategically, that there is oligoplistic competition in generation, and that one of the generators, the incumbent, owns part of the transmission firm. We then study the effect of this partial ownership in a numerical model which is calibrated on the Belgian market. The model captures two kinds of partial ownership interactions: passive ownership, where the generation firm simply cashes its share of the transmission firm's profit without having a direct impact on its decision process, and active ownership, where the generator has a direct influence on the transmission firm's decision process. It is shown that ownership of the network operator by the incumbent generator reduces double marginalization (= welfare improving) but also reduces entry in the generation market (= welfare decreasing).
\end{abstract}

Keywords: vertical integration, unbundling, cross-ownership, electricity

JEL-codes: L13, L22, L43, L94 


\section{The potential impact of cross-ownership in transmission: An application to the Belgian electricity market ${ }^{*}$}

\section{INTRODUCTION}

Until the late nineties, electricity sectors in many countries were dominated by firms which had local monopolies. For example, the Belgian electricity sector was dominated by one utility, Electrabel, that owned about $90 \%$ of generation capacity. SPE, a smaller generator, owned the largest part of the remainder. These two companies also jointly owned and operated the transmission grid, and controlled about $80 \%$ of the distribution and retail market.

At that time, and under the pressure of European legislation ${ }^{1}$, the decision was taken to 'liberalise' or restructure the electricity industry. The basic argument was that such an operation would improve the functioning and the efficiency of the sector as a whole, and would eventually result in reduced average electricity prices. However, one of the essential conditions for a successful restructuring is unbundling. The general idea of unbundling is to separate competitive from non-competitive activities. Competition should be introduced in those markets where it is feasible and viable, i.e. in generation and retail. Activities that are featured by large economies of scale, such as transmission and distribution transport, should remain under regulation as they are recognised to be natural monopolies.

Efficiency improvements can indeed be realised to the extent that effective competition and regulation can be introduced. However, unbundling as such might not result in improved efficiency if competition in generation remains imperfect or if transmission is not properly regulated. One consequence of this could be the creation of successive mark ups, the so-called double marginalisation problem ${ }^{2}$.

Given a situation with imperfect competition in generation or imperfect regulation of the network operator, it is not clear whether perfect unbundling will result in a better outcome in terms of efficiency and welfare than in the initial situation, with vertically integrated firms. On the one hand, vertical integration creates a social cost, as it allows the vertically integrated generator to abuse its position to prevent entry in generation. On the other hand, vertical integration might also create economies of scope (for example, reduced coordination problems) and (partially) reduce the double marginalisation problem that could occur if the restructuring is insufficient.

Early 2004, the European Commission published its third benchmarking report on the implementation of the internal electricity and gas market ${ }^{3}$. The report describes the early 2003 status of the electricity market in the current and the future EU member states and Norway. The Commission concludes that more than $30 \%$ of the European transmission firms are to some extent still vertically integrated with the incumbent generator(s) in the sense that the incumbent owns a non-marginal share of the

The authors are indebted to Jim Bushnell, Severin Borenstein, Ben Hobbs, Stef Proost, Yves Smeers and Jian Yao for their valuable comments. Any errors remaining errors are the author's responsibility.

See the European Directive 96/92/EC of the European Parliament and of the Council of 19 December 1996 concerning common rules for the internal market in electricity. Published in the Official Journal L 027 on 30 January 1997.

2 See for example Tirole (1988) for a discussion of double marginalisation.

See European Commission (2004). 
transmission company. Apparently, full unbundling has not been achieved (yet) in a large number of countries.

It is the purpose of this paper to look at the impact of (partial) unbundling on the electricity market outcome. The focus will be on how (partial) unbundling affects the strategic behaviour of the firms (the double marginalisation problem, bargaining power) and not on the economies or diseconomies of scope that would be generated.

Therefore, this paper explicitly models partial unbundling and the competitive structure in generation and it looks at the impact of both on the electricity market. Essentially, we assume unbundling of generation and transmission, while allowing for some degree of interaction between the firms via partial ownership. Generation firms are partial owners of the transmission firm, which allows them to capture some of the profits of the latter. This ownership can either be passive or active, depending on what is assumed about the generators' ability to influence the transmission firm's decision process.

Partial ownership is said to be passive, when the generation firm cashes a part of the transmission firm's profit without having a direct impact on the decision process of the latter. Partial ownership is of an active nature, if the generator has a direct influence on the transmission firm's decision process ${ }^{4}$.

The formal representation of the partial ownership structure is introduced and discussed in section 3.

We assume the network operator to act strategically, because we think that he has some scope for abusing its market power, especially in the long run. In the short run, i.e. the time frame corresponding to the spot market, the network operator is often strictly regulated. For example, in many countries the regulator imposes transmission tariffs equal to the marginal cost of transmission ${ }^{5}$. In other words, the network operator does not play a strategic role in the spot market ${ }^{6}$. In the long run, however, the network operator has much more discretionary power. He makes a lot of non-recurring decisions, such as investing in new transmission lines, or setting the appropriate reliability level of the network. These decisions are very difficult to regulate ex-ante, and the regulator gives a lot leeway to the network operator concerning these decisions. Even ex-post it is difficult to evaluate the performance of the network operator. As a result, the network operator has a lot of strategic power in the long run operation of the network. This argument will be elaborated further in section 2.

In contrast with most of the literature, the paper explicitly models the long term strategic behaviour of the network operator by distinguishing two stages. In the first stage, the network operator acts strategically and maximizes profits, while taking into account that the generation firms own a share in the transmission company. We do not model the subtle decisions that the network operator can take in the first stage. Instead we assume that the network operator can set a nodal surcharge for using the network.

In the second stage, the network operator sets the transmission prices equal to the short run marginal cost of transmission. All generators take transmission prices and surcharges as given, while deciding

4 See Bresnahan and Salop (1986) for a discussion of alternative partial ownership arrangements, ranging from passive to active forms of ownership. These arrangements are, however, all situated within the standard non-cooperative oligopoly model with horizontal interactions between firms. This paper considers partial ownership structures between firms in a vertical relation.

5 For example, the FERC encourages the use of the standard market design in the US. The standard market design prices transmission constraints on the basis of marginal congestion costs. Nordpool (Norway, Sweden, Finland and Denmark) uses market splitting to deal with congestion, and prices at marginal costs.

6 In a even shorter time frame, corresponding to the real time operation of the network, the network operator has almost unlimited freedom in preventing outages, securing the security of the network etc.. . 
about the generation level in each of their plants and about the level of sales to different consumers. Consumers are assumed to be price takers.

We use a numerical simulation model, calibrated on the basis of data from the Belgian electricity market. The model incorporates the major characteristics of the demand as well as of the supply side of the market in Belgium, but the model can easily be applied to other countries.

Apart from two benchmark scenarios, three alternative scenarios are developed for the generation market. We have one benchmark scenario with a welfare maximising and one with a profit maximising transmission firm. Both scenarios assume perfect competition in generation, and unbundled generation and transmission activities. It is always assumed that the transmission firm is subject to a budget constraint. The other three scenarios assume a profit maximising transmission firm. The first alternative scenario assumes perfect competition in generation. In the second scenario, the generation market is a monopoly. As the Belgian electricity market was highly concentrated (the largest generator had $83 \%$ of the production capacity), this scenario could be considered as representing the preliberalisation situation in generation. The third scenario considers three Cournot players in generation. This can be interpreted as a market where some of the monopolist's production capacity is virtually auctioned, a mechanism that is currently being implemented in Belgium.

For each of the alternative scenarios we study the impact of partial ownership of the transmission firm on the market outcome. Three ownership cases are distinguished, no partial ownership (full unbundling), partial ownership ( $70 \%$ of the transmission firm owned by the incumbent generator) and full ownership (vertical integration).

Section 2 reviews some relevant literature and discusses the strategic behaviour of the network operator in a network setting. Section 3 describes the model while section 4 describes the Belgian grid and generation characteristics and other data that were used to run the model. Section 5 discusses simulation results and, finally, section 6 presents conclusions.

\section{MODELLING THE ELECTRICITY MARKET}

\subsection{Electricity generation}

In the literature on the modelling of electricity markets, two types of equilibrium have been developed to model imperfect competition in a multi-good market: the multi-unit auction and the supply function equilibrium.

In the multi-unit auction, generators bid a price for each plant at which they are willing to supply given capacities $^{7}$. The equilibrium price, determined as the price that clears the market, is applied to all inframarginal units ${ }^{8}$. Wolfram (1998) uses the multi-unit auction approach to find empirical evidence that, in the England \& Wales market, large players effectively try to use their market power in this way. A drawback of multi-unit auctions is that they are particularly hard to model, and that they do not always have a Nash equilibrium.

The supply function equilibrium concept is based on Klemperer and Meyer (1989). Generators choose a continuous and differentiable supply function, which, for each price, specifies the quantity they are willing to generate. Again, the electricity price is established as the market clearing price. An example

\footnotetext{
See for instance the models of von der Fehr and Harbord (1993).

8 Other types of auctions can also be considered.
} 
of the supply function equilibrium approach is Green and Newbery (1992). These authors apply the Klemperer and Meyer model to the two largest generators in the English market.

One of the major drawbacks of the two approaches discussed above is that the spatial structure of the electricity market, and therefore the impact of transmission constraints, is omitted for reasons of complexity. Most researchers therefore opt for a Cournot market, while dropping some of the multigood aspects of the actual market. This latter approach is supported by an empirical study of Wolak and Patrick (2001) who suggest that Cournot competition is an appropriate representation of the electricity generation market.

This paper will follow the Cournot approach to model the electricity generation market. However, even Cournot models become quite cumbersome when simulations are made for larger networks with transmission constraints. This is the case because generators realize that, with scarce transmission capacity, transmission prices can be influenced, and congestion can be created. Cournot-Nash equilibriums are then no longer guaranteed to exist, and rationing rules or arbitrageurs need to be added to the model (Willems (2002)). This paper therefore assumes that generators behave à la Cournot in the energy market (buying and selling of electricity), but are price takers in the transmission market, an approach that is inspired by the models of Smeers and Wei (1997) and Wei and Smeers (1999).

\subsection{Network operation}

Next to the question of how generators perceive transmission prices, there is also the question of how the transmission firm sets prices. Also with respect to this question, different assumptions can be made. Examples are marginal cost pricing (Smeers and Wei (1997)), regulated pricing (Wei and Smeers (1999)), and strategic pricing, which is used in this paper. A short discussion of the first two approaches is provided in Pepermans and Willems (2004).

\section{Strategic pricing}

Smeers and Wei (1997) assume that transmission is priced according to its marginal cost. Underlying this pricing rule are the assumptions that $(A)$ marginal cost pricing is optimal, and $(B)$ the network operator can be perfectly regulated and therefore has no freedom in operating the network.

Although we think that the optimality of marginal cost pricing can be questioned for reasons of efficiency, we observe in the real world that regulators often oblige the network operator to use marginal cost pricing for the short run operation of the network ${ }^{9}$. Nevertheless, these charges are optimal in the limit, and they mimic the prices that would be set by a perfectly competitive network operator.

\footnotetext{
The optimality of marginal cost pricing can be questioned for at least two reasons. First, with increasing returns to scale in network operation, marginal cost pricing does not guarantee sufficient revenue for cost recovery. If the transmission firm's losses cannot be subsidised via transfers, then other pricing rules, implying prices above marginal cost, will have to be applied. Without transmission constraints and with perfect competition in generation, these prices would be the well known Ramsey prices.

Second, it would be optimal for a welfare maximising transmission firm to deviate from marginal cost pricing if competition in generation is imperfect. Imperfect competition would result in output levels below the welfare optimum and subsidising the generator(s) to increase output and, hence, to decrease dead-weight losses, would be optimal. If it would be costless for a welfare maximising network operator to extract revenue from the users of the network, then the first best outcome could be achieved, even if there is a monopolist in generation. A combination of a lump sum tariff (equal to the generator's profit) and a negative transmission tariff would induce the generator to produce the first best outcome.
} 
Despite a very strict regulation of the short run operation of the network, we think that the network operator still has a lot of discretionary power in the long run operation of the network that allows exploiting market power ${ }^{10}$. The following examples illustrate the point:

- In order to recover costs, network operators are allowed to charge the network users a surcharge. These charges have to fit in a regulatory framework, set by the regulator, and are often based upon demand characteristics.

- In many cases the network operator will suggest how and where to reinforce the grid (investing in new transmission lines, capacitor banks...). Clearly, the type and location of these investments will influence the market outcome.

- The network operator also decides how to manage network risks and what security and safety levels to maintain.

- Network operators also take decisions about must run plants. These plants are needed for network stability and as such they enjoy local market power.

- Some network operators can define different zones in their market, each having a different price.

- Some network operators are involved in setting up and running auctions for the procurements of reserve capacity, the balancing market and other type of markets. Additionally, some network operator sell physical or financial transmission rights.

This paper studies the long run strategic behaviour of the network operator, and assumes that in the short run transmission prices are set equal to marginal transmission cost. We do not model the subtle ways in which the network operator can potentially influence the market outcome in the long run. Neither will we implement a detailed regulation mechanism. Instead, we take a shortcut and assume that the network operator can strategically set a nodal surcharge for using the network. Network users will pay both the surcharge and the marginal transmission cost. In the future, a more refined model can be constructed to model the role of the network operator, and different types of regulations.

The paper models the decision process as a two stage game. In the first stage, the network operator acts strategically by setting transmission surcharges at each consumption node and generation node. The network operator maximizes his objective function, taking into account the effect of its pricing decision on the strategic behavior of the players in the second stage.

In the second stage, the network operator has no freedom and prices at marginal costs. Generators behave a la Cournot, taking the nodal transmission surcharges and the marginal transmission prices as given. Except for the transmission surcharges, this second stage is the congestion pricing model of Smeers and Wei (1997).

The current model differs from the regulated prices model of Wei and Smeers (1999) as, in the latter model, transmission charges are set on the basis of some regulatory rule, whereas in our model we assume transmission charges to be set by the network operator.

We think that the two-stage presentation of the network operator is reasonable for most electricity markets. The standard model of locational marginal cost pricing (LMP) is fairly well understood, and the regulator can fairly easily oblige the network operator to price at marginal transmission cost in the day-ahead market. In the longer run, the network operator is less strictly regulated, and has a lot of freedom. Our model provides an upper limit of the market power of the network operator.

\footnotetext{
10 Also the real time operation of the market is difficult to regulate because a lot of unpredicted events might happen, which are not described ex ante. This might also create problems of (local) market power, etc. Our model is not designed to model these types of strategic behavior.
} 


\section{Equivalence result}

Finally note that, in this model, the network operator receives two types of revenue: (1) nodal generation and consumption surcharges (set strategically), and (2) the congestion charges which are set equal to the marginal costs of the transmission line. If (as we assume) the network operator has perfect information about generation costs and if there is no uncertainty between the first stage and the second stage, then we can assume without loss of generality that the network operator does not charge the congestion charges in the second period, but includes them in the first stage of the game. This insight simplifies the modeling of the electricity market.

\subsection{Partial ownership}

As mentioned in the introduction, the purpose of this paper is to look at the effect of ownership structures of vertically related firms. In order to focus on the essentials, this section assumes one generation firm, the incumbent, owning a share of the transmission firm ${ }^{11}$. We distinguish two ways in which this partial ownership can affect the strategies of the players. The first effect is of a passive nature. The cross ownership relation aligns the objectives of the two players because they now share each other's gains and losses. The second effect is of a more active nature. Via its partial ownership, the shareholder will try to influence the decisions of the firm in which it has a stake. Both effects will be discussed in this section.

To set the scene, let $\Pi_{I n c}^{G e n}$ and $\Pi^{T r}$ be the operational profit from generation and transmission activities, respectively. The consolidated profit of the incumbent generator $\widehat{\Pi}_{I n c}^{G e n}$ is equal to the sum of its own operating profit $\Pi_{I n c}^{G e n}$ and its share $\rho$ of the network operator's profit $\Pi^{T r}$, i.e.

$$
\widehat{\Pi}_{I n c}^{G e n}=\Pi_{I n c}^{G e n}+\rho \Pi^{T r}
$$

The consolidated profit of the network operator $\widehat{\Pi}^{T r}$ is equal to its share $1-\rho$ in its own profits, or

$$
\widehat{\Pi}^{T r}=(1-\rho) \Pi^{T r}
$$

The idea that the generation firm could also have an impact on the decision process of the transmission firm is captured by writing the objective function of the latter as a weighted sum of the consolidated profits of the incumbent and the transmission firm, i.e.

$$
\Gamma^{T r}=\widehat{\Pi}^{T r}+\omega \widehat{\Pi}_{I n c}^{G e n}
$$

In equation (3), $\Gamma^{T r}$ is the transmission firm's objective function. Note that $\Gamma^{T r}$ is not the consolidated profit of the transmission firm.

\footnotetext{
11 In section 3, a more general assumption will be introduced with respect to the number of generation firms that have a stake in the transmission company. The simulations will again focus on the case where one firm, the incumbent, has a stake in the transmission firm.
} 
The parameter $\omega \geq 0$ reflects the bargaining power of the generator in the transmission firm. Clearly, $\rho$, the share of the transmission firm owned by the generator, is likely to have an effect on $\omega$, the bargaining weight. We assume $\omega^{\prime}(\rho) \geq 0$, i.e. the bargaining power is a non-decreasing function of the share owned by the generation company. The larger the ownership share, the more influence one has in the decision making process of the transmission company.

Using (1) and (2), we can rewrite (3) as

$$
\Gamma^{T r}=\omega \Pi_{I n c}^{G e n}+(1-(1-\omega) \rho) \Pi^{T r}
$$

Some special cases can be considered, depending on the value of $\rho$ and $\omega$.

\section{Passive ownership}

First, consider the case of passive ownership. Under passive ownership, the generation firm and the network operator each maximize their consolidated profit, but the incumbent generator has no direct influence in the decision process of the transmission firm. Formally, this case is captured by having $\omega=0$ and $0 \leq \rho \leq 1$. As can be seen from equation (2), passive ownership merely scales down the profit of the network operator, and does therefore not change the actions taken by the network operator. However, passive ownership does change the priorities of the incumbent, because now the incumbent's actions depend on its share in the transmission firm. The equations (1) and (4) would reduce to

$$
\begin{aligned}
\widehat{\Pi}_{I n c}^{G e n} & =\Pi_{I n c}^{G e n}+\rho \Pi^{T r} \\
\Gamma^{T r} & =(1-\rho) \Pi^{T r}
\end{aligned}
$$

\section{Active ownership}

With active ownership, the generation firm uses its ownership share to influence the decision process of the transmission firm. In equation (4), we now have $\omega>0$, i.e. the generator has some bargaining power in the transmission firm. The objective functions of the players then become

$$
\begin{aligned}
\widehat{\Pi}_{I n c}^{G e n} & =\Pi_{I n c}^{G e n}+\rho \Pi^{T r} \\
\Gamma^{T r} & =\omega \Pi_{I n c}^{G e n}+(1-(1-\omega) \rho) \Pi^{T r}
\end{aligned}
$$

\section{Full integration and unbundling}

The equations (6) also cover full integration and unbundling as special cases. Indeed, with $\rho=1$, we have a fully integrated generation and transmission company, i.e.

$$
\begin{aligned}
\widehat{\Pi}_{I n c}^{G e n} & =\Pi_{I n c}^{G e n}+\Pi^{t r} \\
\Gamma^{T r} & =\Pi_{I n c}^{G e n}+\Pi^{t r}
\end{aligned}
$$


In other words, bargaining power becomes irrelevant, as can be seen from (4). With $\rho=1$, the bargaining weight $\omega$ becomes a scaling factor that does not affect decisions. The objectives of the network operator and the incumbent are perfectly aligned as they reflect the profit of the integrated firm. There is no reason for the incumbent generator to actively influence the decisions of the network operator because the network operator already has the right incentives (seen from the incumbent's viewpoint).

On the other hand, with $\omega=\rho=0$, we have unbundling of ownership in generation and transmission, i.e.

$$
\begin{aligned}
\widehat{\Pi}_{I n c}^{G e n} & =\Pi^{G e n} \\
\widehat{\Pi}^{t r} & =\Pi^{t r}
\end{aligned}
$$

\section{THE MODEL}

Define the sets $F$ and $G$ as the sets of generation firms and generation plants. Let $G_{f}$ be the set of generation units owned by generation firm $f \in F$. With $I$ being the set of network nodes, $G_{i}$ denotes the generation plants at node $i \in I$, and $G_{f i}$ the generation plants at node $i$ owned by firm $f$. The network contains a number of nodes $i \in I$.

For notational simplicity, the model will be further described as if it concerned a one period model, i.e. a model that does not distinguish between peak and off-peak periods. However, the numerical simulations discussed in section 4 also cover a case that differentiates between peak and off-peak demand in a 4-period model.

The model distinguishes three types of players: consumers, generation firms and the network operator.

\section{Consumers}

Consumers are price takers. At node $i$, they consume $s_{i}$ units of electricity. Their inverse demand for electricity, denoted as $p_{i}\left(s_{i}\right)$, is downward sloping and concave. Consumer prices include compensation for both the generation and the transmission of electricity.

\section{Generation firms}

Generation firm $f \in F$ maximizes profits, while acting as a price taker in transmission. At node $i$, it owns the generation plants $g \in G_{f i}$.

Electricity generation in plant $g$ is $q_{g}$ and the generation cost is $C_{g}\left(q_{g}\right)$. Total generation costs are convex, with fixed generation costs normalized to zero. The generation capacity of plant $g$ is labelled $\bar{q}_{g}$. Output should be nonnegative, and cannot exceed available generation capacity. Therefore, we have

$$
0 \leq q_{g} \leq \bar{q}_{g}
$$

Let $\Pi_{f}^{G e n}$ and $\Pi^{\text {tr }}$ be the operating profits of generation firm $f$ and of the transmission firm, respectively. Then, we write the total consolidated profit $\widehat{\Pi}_{f}^{\text {Gen }}$ of the generation firm $f$ as 


$$
\widehat{\Pi}_{f}^{G e n}=\Pi_{f}^{G e n}+\rho_{f} \Pi^{T r}
$$

with $\rho_{f}$ being the share of the transmission company owned by generation firm $f$. This formulation covers many situations. For example, with $\rho_{f}=0, \forall f \in F$ generation and transmission would be fully separated. With $\rho_{i n c}=1$ and $\rho_{f}=0, \forall f \neq i n c$, we would have the special case where the incumbent generation firm would be the single and full owner of the transmission firm.

\section{The network operator}

As described in the previous section, the network operator does not purely maximize consolidated profits. Instead, the generators actively influence the actions of the network operator. The extent to which partial ownership results in the ability to influence the transmission firm's decision process is captured by the parameter $\omega_{f}$, reflecting bargaining power of the generation firm $f$. Formally, this idea is captured by writing the objective function of the transmission company as

$$
\Gamma^{T r}=\widehat{\Pi}^{T r}+\sum_{f \in F} \omega_{f} \widehat{\Pi}_{f}^{G e n}
$$

The transmission company sets a nodal transmission charge $\tau_{i}^{c}$ for consumers and $\tau_{i}^{p}$ for generators. This is the per unit payment generators have to make for injecting power, and that consumers have to pay to take power from the grid. These charges can be different. For instance, a generator who generates electricity in node $i$ and sells electricity in node $j$ will pay $\tau_{i}^{p}+\tau_{j}^{c}$. Only the sum of the consumer and generation transmission charge is important, and therefore one of the charges can be set equal to zero without loss of generality.

As explained before, the model has two stages. In the first stage, the transmission operator sets transmission prices. In the second stage, generation firms play a Cournot game in which transmission prices and their competitor's quantities are assumed as given. The next subsection describes the second stage of the game.

\subsection{The second stage}

Each firm $f$ observes the transmission charges $\tau_{i}^{p}$ and $\tau_{i}^{c}$ as set by the network operator and plays a Cournot game. A firm $f$ collects revenue by selling $s_{f i}$ units of electricity at node $i$ at the per unit price $p_{i}$. Firms also set the production level $q_{g}\left(g \in G_{f}\right)$ at each of their plants. Their competitors' sales in node $i$, denoted by $\tilde{s}_{-f i}$, are taken as given. Apart from generation costs, firms also pay a transmission cost $\tau_{i}^{p}$ for injecting electricity to the network at node $i$, and $\tau_{i}^{c}$ for the delivery of electricity to node $i$. This results in the consolidated profit function for generation firm $f$,

$$
\widehat{\Pi}_{f}^{G e n}=\sum_{i \in I}\left(p_{i}\left(s_{i}\right)-\tau_{i}^{c}\right) \cdot s_{f i}-\sum_{i \in I} \sum_{g \in G_{f i}}\left[C_{g}\left(q_{g}\right)+\tau_{i}^{p} q_{g}\right]+\rho_{f} \Pi^{T r}
$$

The nodal price $p_{i}\left(s_{i}\right)$ that is received by generator $f$ depends on the total sales in that node, i.e.

$$
s_{i}=s_{f i}+\tilde{s}_{-f i}
$$


where a tilde indicates that the variable is considered as given. In equation (11), the first term reflects revenues from electricity sales net of transmission charges paid at the consumption nodes. The second term reflects generation costs and transmission charges to put the electricity on the network. Summarizing, we have the following maximization problem for a generator:

$$
\begin{aligned}
& \operatorname{Max}_{s_{f i}, q_{g}\left(g \in G_{f}\right)} \widehat{\Pi}_{f}^{G e n}=\sum_{i \in I}\left(p_{i}\left(s_{i}\right)-\tau_{i}^{c}\right) \cdot s_{f i}-\sum_{i \in I} \sum_{g \in G_{f i}}\left[C_{g}\left(q_{g}\right)+\tau_{i}^{p} q_{g}\right]+\rho_{f} \Pi^{T r} \\
& \text { s.t. } 0 \leq q_{g} \leq \bar{q}_{g} \quad\left(\underline{\mu}_{g}, \bar{\mu}_{g}\right) \quad \forall g \in G_{f} \\
& \sum_{i \in I} s_{f i}=\sum_{g \in G_{f}} q_{g} \quad\left(\lambda_{f}^{p}\right) \\
& s_{i}=s_{f i}+\tilde{s}_{-f i} \quad \forall i \in I
\end{aligned}
$$

As noted before, the first constraint reflects generation capacity constraints. The second constraint represents the energy balance at the firm level, i.e. total output should equal total sales. The last constraint represents demand. This constraint has no multiplier as it is substituted into the objective function and the other constraints before derivatives are taken.

The following first order conditions are then derived:

$$
\begin{gathered}
\frac{\partial C_{g}\left(q_{g}\right)}{\partial q_{g}}+\tau_{i}^{p}-\rho_{f} \frac{\partial \Pi^{T r}}{\partial q_{g}}+\underline{\mu}_{g}-\bar{\mu}_{g}=\lambda_{f}^{p} \quad \forall g \in G_{f i}, \forall i \in I \\
p_{i}+\frac{\partial p_{i}\left(s_{i}\right)}{\partial s_{i}} s_{f i}-\tau_{i}^{c}+\rho_{f} \frac{\partial \Pi^{T r}}{\partial s_{i}}=\lambda_{f}^{p} \quad \forall i \in I
\end{gathered}
$$

These are the standard first-order conditions for profit maximization, i.e. as long as generation constraints are not binding, marginal revenue equals marginal cost in all market segments. The Lagrange multiplier of the energy balance constraint $\lambda_{f}^{p}$, is the value of energy in the network for generation firm $f$. This value is different for every firm.

Cost minimization requires that each firm equalizes the sum of the marginal cost and the generation charge at all generation plants. Profit maximization requires that marginal revenues net of consumption charges are equalized.

Each firm's reaction function with respect to the sales $s_{-f i}$ and the transmission charges, $\tau_{i}^{c}$ and $\tau_{i}^{p}$ can be derived from the equations (13) and (14).

The multipliers $\underline{\mu}_{g}$ and $\bar{\mu}_{g}$ are positive, and satisfy the complementarity conditions:

$$
\begin{array}{ll}
\underline{\mu}_{g} \geq 0 & \underline{\mu}_{g} \cdot q_{g}=0 \\
\bar{\mu}_{g} \geq 0 & \bar{\mu}_{g} \cdot\left(\bar{q}_{g}-q_{g}\right)=0
\end{array}
$$

\section{Electricity transmission}

Electricity transport is subject to physical constraints that have an impact on the power flow through the network and therefore potentially also on the pricing of transmission services. The approach 
followed in this paper, is to look at active power and to model a simplified DC flow model without losses $^{12}$. A detailed description of the thermal constraints, line flow equations, energy balance constraints and $n-1$ security constraints is not provided in this paper. The interested reader is referred to section 3 of Pepermans and Willems (2004) for a more elaborate description of these equations.

\subsection{The first stage}

The network operator is a profit-maximizing firm, but his objective function (equation (10)) also reflects the stakes of the generation companies that partially own the transmission company. The objective is maximized by setting consumption and generation transmission charges $\left(\tau_{i}^{c}\right.$ and $\left.\tau_{i}^{p}\right)$, which can be differentiated over the nodes. It is assumed that the cost of providing transmission services can be split into operating costs and capacity costs. In the present model, operating costs and network losses are neglected. Therefore, only the capacity costs $B$ remain.

The network operator's operational profit is equal to:

$$
\Pi^{T r}=\sum_{i \in I}\left(\tau_{i}^{c} s_{i}+\tau_{i}^{p} q_{i}\right)-B
$$

The first term between brackets is the revenue of selling transmission services to consumers at node $i$. The second term is the revenue of selling transmission to the generators. The last term represents capacity costs. By assumption, capacity costs are fixed.

The transmission firm maximises his objective function (10)

$$
\Gamma^{T r}=\sum_{f \in F} \omega_{f} \Pi_{f}^{G e n}+\left(1-\sum_{f \in F}\left(1-\omega_{f}\right) \rho_{f}\right) \Pi^{T r}
$$

subject to the energy balance at the firm level,

$$
\sum_{i \in I} s_{f i}=\sum_{g \in G_{f}} q_{g} \quad \forall f \in F
$$

the Cournot behaviour

$$
\begin{gathered}
\frac{\partial C_{g}\left(q_{g}\right)}{\partial q_{g}}+\tau_{i}^{p}\left(1-\rho_{f}\right)+\underline{\mu}_{g}-\bar{\mu}_{g}=\lambda_{f}^{p} \quad \forall g \in G_{f i}, \forall i \in I \\
p_{i}+\frac{\partial p_{i}\left(s_{i}\right)}{\partial s_{i}} s_{f i}-\tau_{i}^{c}\left(1-\rho_{f}\right)=\lambda_{f}^{p} \quad \forall i \in I
\end{gathered}
$$

\footnotetext{
12 Such a model assumes that line resistance is small relative to reactance, that voltage magnitudes are the same at all nodes, and that voltage angles between nodes at opposite ends of a transmission line are small. Engineers often use the linearized model of the network for long term planning.

The alternative, AC-power flow, was used in a previous version of the program, but did not give fundamentally different results.
} 
and the network equations. Furthermore, note that the two constraints that describe the Cournot behaviour of the generator are non-convex. Therefore the problem does not need to have a unique local optimum.

\section{Welfare maximization}

As a benchmark for the simulations, we also present the model outcome if the transmission firm would behave as a welfare maximizer, subject to a budget constraint. In that case, the problem would be to maximise

$$
W=\sum_{i \in I} \int_{0}^{s_{i}} p_{i}(t) d t-\sum_{g \in G} C_{g}\left(q_{g}\right)
$$

subject to the network constraints, the behavioural equations of the generators and the budget constraint:

$$
\sum_{i \in I}\left(\tau_{i}^{c} s_{i}+\tau_{i}^{p} q_{i}\right)-B=\Pi^{t r} \geq 0
$$

This latter constraint is added in order to avoid that the network operator goes bankrupt.

\section{DATA AND CALIBRATION}

Belgium enacted the EU Directive 96/92, commonly called the electricity directive, with the federal law of 29 April $1999^{13}$, defining the federal framework for the opening of the electricity market. Broadly speaking, the federal government is responsible for aspects of electricity generation, for the transmission grid $^{14}$ and for pricing issues, including transmission and distribution tariffs. The three Belgian regions (Brussels, Flanders, Wallonia) are responsible for the distribution and local transmission of electricity over networks with a voltage level less than or equal to $70 \mathrm{kV}$. Regions also have authority over retail activities (except prices), renewables and the rational use of energy programmes. The three regions have also transposed the European Directive into the regional legislation ${ }^{15}$. The Belgian electricity market is gradually opening for competition, starting with large industrial consumers and moving down to retail activities. Currently, Flanders has competition in retail, while Brussels and Wallonia plan to have retail competition in 2007.

A Federal Regulatory Commission, the CREG, has been installed in 2000. The CREG oversees electricity generation (licensing...) and transmission, rubberstamps investment projects of the network operator and sets the price for transmission based upon a cost-plus principle.

Three regional regulatory bodies ${ }^{16}$, one per region, are monitoring the operation of the electricity market at the regional level. These regulators are responsible for establishing the technical legislation regulating the distribution networks and for defining the eligibility conditions for customers connected to this grid (mostly small and medium enterprises and households).

\footnotetext{
3 Published on 11 May 1999.

4 This is the transport of electricity at a voltage level above $70 \mathrm{kV}$.

15 For Flanders, the decree of 17 July 2000, for Wallonia, the decree of 12 April 2001 and for Brussels, the decree of 19 July 2001.

16 In Flanders, the VREG, in Wallonia, the CWAPE and in Brussels the IBGE-BIM.
} 
The next 4 subsections discuss the transmission, generation and demand data that served as an input for the model. Finally, subsection 4.5 describes the calibration procedure. Unless stated otherwise, the data reflect the Belgian electricity system in 2002.

\subsection{The transmission grid}

\section{Ownership structure}

In June 2001, Electrabel and SPE, the two incumbent generators, established a daughter company ELIA, to operate the transmission grid. In order to comply with the federal requirements of independency, Electrabel and SPE had to reach an agreement with the federal government on the future shareholder structure of ELIA. In 2003, an agreement was reached. The Belgian municipalities took a $30 \%$ participation in the network operator, while Electrabel and SPE owned the remaining $70 \%$. It is also agreed that, in the near future, Electrabel and SPE will reduce their share from $70 \%$ to $30 \%$, by selling $40 \%$ of the shares to the private sector ${ }^{17}$.

\section{The transmission grid}

Figure 1 shows the network as it has been modelled. It consists of 55 nodes and 92 lines, including all Belgian $380 \mathrm{kV}$ and $220 \mathrm{kV}$ transmission lines, but also some $380 \mathrm{kV}$ lines in The Netherlands and France. These latter lines are included because they are important for the flows inside the Belgian grid. The full lines on the graph are $380 \mathrm{kV}$ lines, the dotted lines are $220 \mathrm{kV}$ lines. The line between Gouy and Avelgem represents several lines of the $110 \mathrm{kV}$ network that connect both nodes. ${ }^{18}$

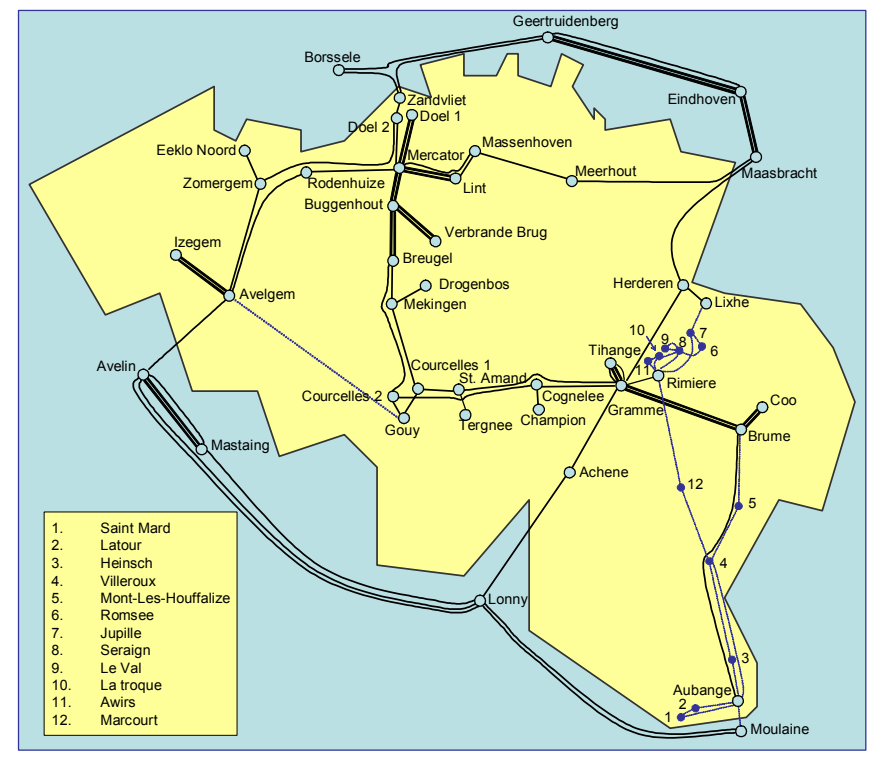

Figure 1: The Belgian high voltage network, situation in 2002.

17 Before the liberalization of the electricity markets, municipalities participated in the distribution companies. Distribution companies had a local monopoly in distribution transport and retail activities, which resulted in significant cash flows for the municipalities. After the liberalization, local governments are no longer allowed to participate in electricity retail, and as a compensation for the cash flow losses, they are promised a compensation by making them shareholders of the high voltage transmission network.

18 Network data was kindly provided by Peter Van Roy and Konrad Purchala of the K.U.Leuven Electrical Engineering Department. More detailed information on origin and destination, voltage level, admittance, thermal capacity... is available upon request. 


\section{Transit}

Transmission capacity at the Belgian - French border is scarce and the lines are congested most times of the year. Also the Dutch - German interconnection is often congested. This separates the joint Belgian-Dutch market from the rest of Europe.

The model takes into account that the Belgian grid is used for relatively large transit flows, generally directed from France to The Netherlands. As a first approximation, we impose an exogenous transit flow of $1000 \mathrm{MW}$ from the south to the north. This transit is assumed to occur in all periods. The foreign generation and load nodes are summarized in Table 1.

Imports from France to Belgium, being about $400 \mathrm{MW}$, are neglected because a correct inclusion would require the modelling of the French generator(s). A more detailed and better modelling procedure for imports should be the subject of further research.

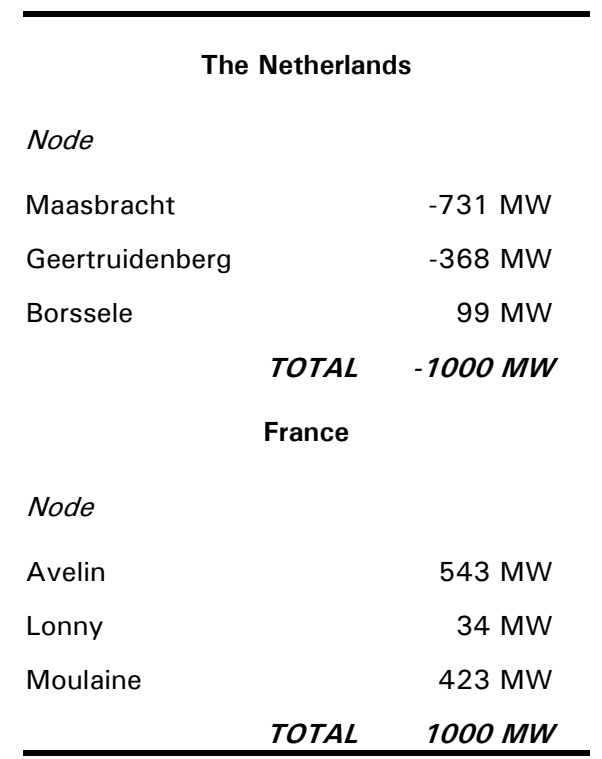

Table 1: Exogenous generation levels at the foreign nodes (Negative numbers are loads).

\subsection{Electricity generation}

\section{The real world}

In 2002, about $15550 \mathrm{MW}$ of generation capacity was available in Belgium, of which about $37 \%$ nuclear, $44 \%$ fossil fuel and $8 \%$ pumped storage plants. Co-generation, renewables and smaller generation units accounted for about $10 \%$ of total installed generation capacity. This capacity is in the hands of three categories of electricity producers: utilities (96\%), auto-producers $(2.5 \%)$ and autonomous generators $(1.5 \%)^{19}$. The capacities owned by the latter two categories are relatively unimportant and are not modelled in detail.

In 2002, utilities covered almost $98 \%$ of domestic production. The largest generator is Electrabel (owned by private sector), followed by SPE (owned by the public sector). Smaller utilities are active in

\footnotetext{
19 Auto-producers are firms (mainly in the chemical and metallurgic sector) that generate electricity to (partially) cover their own needs. In principle, these producers do not sell electricity to the market. Autonomous generators generate electricity as a complementary activity, for example via waste incineration. These firms sell their output to third parties.
} 
the field of renewable energy and co-generation. Electrabel has a quasi-monopoly and owns about $90 \%$ of the Belgian generation capacity.

\section{The model}

The model incorporates relevant data on 51 generation units located in the grid. Only nuclear, fossil fuel and pumped storage generation units owned by the utilities are taken into account. The total available generation capacity in the model equals $13405 \mathrm{MW}^{20}$.

Approximately $1070 \mathrm{MW}$ of smaller generation plants, mostly owned by auto-producers and autonomous generators, are not included in the model. These are mainly combined heat and power generation units (970 MW), and some small hydro units (90 MW). We assume that in any time period, $50 \%$ of these plants produce electricity.

Two pumped storage plants that can store energy in the form of a water reservoir are also included in the model. When generation costs are low, these plants consume electricity and pump water to a higher level. When generation costs are high, the reservoir is emptied and electricity is produced. The underlying decision process is not modelled. We assume these plants to generate electricity during peak periods at a marginal cost of $€ 13$ per MWh., In peak periods, these plants are counted as part of the consumption side ${ }^{21}$.

Table 2 summarises for each fuel type the key characteristics of the installed generation capacity in Belgium. The second column gives the number of plants and the third gives the marginal generation cost for each technology, when $50 \%$ of a plant's generation capacity is used.

In the simulations section, we present three alternative scenarios w.r.t. the structure of the generation market. First, we assume a generation monopoly, i.e. all generation units are owned by one profit maximizing generator. The second scenario considers three profit maximizing generators, having an approximate market share in generation capacity of $43 \%, 30 \%$ and $27 \%$, respectively. The columns four to six in Table 2 provide information on the assumed generation ownership structure in this case. Finally, the third scenario assumes perfect competition in generation.

20 Some of the data was kindly provided by Leonardo Meeus and Kris Voorspools of the K.U.Leuven Electrical and Mechanical Engineering Departments, respectively. Data was also taken from several editions of the BFE statistical yearbook and the annual report of Electrabel.

21 A better modelling of the pumped storage plants would require to take into account the capacity constraint of the water reservoir, and to make the decisions of whether to consume or to generate endogenous. 


\begin{tabular}{|c|c|c|c|c|c|c|}
\hline \multirow{2}{*}{ Plant type } & \multirow{2}{*}{ Nr of units } & \multirow{2}{*}{$\begin{array}{c}C_{g} \\
\text { (€ per } \mathbf{M W h})\end{array}$} & \multicolumn{3}{|c|}{ Ownership under Cournot (MW) } & \multirow{2}{*}{$\begin{array}{l}\text { Installed capacity } \\
\text { (MW) }\end{array}$} \\
\hline & & & Gen 1 & Gen 2 & Gen 3 & \\
\hline Conv. Coal & 9 & 20 & & 219 & 1194 & 1413 \\
\hline Conv. Coal + repowering & 4 & 19 & & 602 & 333 & 935 \\
\hline Conv. Fuel & 2 & 40 & & & 257 & 257 \\
\hline Conv. Gas & 2 & 21 & & 522 & & 522 \\
\hline Diesel Motor & 2 & 58 & & & 148 & 148 \\
\hline Gas Turbine & 3 & 45 & & & 178 & 178 \\
\hline Nuclear & 7 & 10 & 5761 & & & 5761 \\
\hline Pumped Storage & 3 & 13 & & 1307 & & 1307 \\
\hline STAG & 8 & 18 & & 1316 & 1358 & 2674 \\
\hline Turbojets & 11 & 59 & & 17 & 193 & 210 \\
\hline \multirow[t]{2}{*}{ Total } & 51 & & 5761 & 3983 & 3661 & 13405 \\
\hline & & & $(43.0 \%)$ & $(29.7 \%)$ & (27.3\%) & $(100.0 \%)$ \\
\hline
\end{tabular}

Table 2: Information about the installed generation capacity.

Each player maximizes profit, taking into account plant characteristics. Generation decisions are described by the first order conditions (13) and (14) and the complementarity conditions (15). The player's generation decisions are highly non-linear at the zero production level and at the maximal capacity of each plant. Therefore, the model in this paper is a Mathematical Program with Equilibrium Constraints (MPEC's). MPECs are a class of problems which are known to be difficult to solve (Luo, Pang et al. (1996)). This paper uses a pragmatic approach to solve them and relaxes the complementarity conditions (15) to

$$
\begin{aligned}
& \underline{\mu_{g}} \cdot\left(q_{g}+\beta_{g}\right)^{\phi_{g}}=\alpha_{g} \\
& \bar{\mu}_{g} \cdot\left(\bar{q}_{g}-q_{g}+\beta_{g}\right)^{\phi_{g}}=\alpha_{g}
\end{aligned}
$$

The parameters $\alpha_{g}, \beta_{g}$ and $\phi_{g}$ are the relaxation parameters of the complementarity conditions. When $\alpha_{g}$ and $\beta_{g}$ become equal to zero, we obtain again the exact complementarity conditions.

After solving for the Lagrange multipliers $\underline{\mu}_{g}$ and $\overline{\mu_{g}}$ in equation (23), the optimal sales decision (19) can be rewritten as

$$
\frac{\partial C_{g}^{s m}\left(q_{g}\right)}{\partial q_{g}}+\tau_{i}^{p}=\lambda_{f}^{p} \quad \forall i \in I, \forall f \in F, \forall g \in G_{f i}
$$

with $\frac{\partial C_{g}^{s m}\left(q_{g}\right)}{\partial q_{g}}$ the smoothed marginal cost function:

$$
\frac{\partial C_{g}^{s m}\left(q_{g}\right)}{\partial q_{g}} \equiv C_{g}+\frac{\alpha_{g}}{\left(q_{g}+\beta_{g}\right)^{\phi_{g}}}-\frac{\alpha_{g}}{\left(\bar{q}_{g}-q_{g}+\beta_{g}\right)^{\phi_{g}}} \quad \forall g \in G
$$


This is the approach followed in the numerical simulations. By smoothing the marginal cost functions of the generators, we make sure that the generators will choose an internal solution, and not one of the boundary generation levels 0 or $\bar{q}_{g}$.

\subsection{Electricity demand}

The model has been calibrated on the basis of Belgian data for electricity demand in $2002^{22}$. In that year the average demand was $9.52 \mathrm{GW}$. Total demand in Belgium was 83.4 TWh in 2002. Figure 2 presents a histogram of demand in Belgium. The histogram is based on periodical observations with a length of 15 minutes. The highest and lowest observed demand levels were $13.7 \mathrm{GW}$ and $5.8 \mathrm{GW}$, respectively.

Obviously, the demand for electricity is not constant when looked at over the period of one year. The current model distinguishes four periods per year (as will be explained later), but does not consider links between these periods. Clearly, taking into account these links would enrich the model and this is seen as a priority for further research. At least four of such potential links can be identified. First, cross-substitution can take place between time periods. For example, demand for electricity during the night will not only depend on the price in that period, but also on the price that is charged during the day. Second, the consumption and generation decisions of the pumped storage plants are linked through time. Third, intertemporal generation constraints exist as generators can increase or decrease output only at a certain speed (ramping constraints). Starting up and shutting down generators is costly and requires time. These constraints are not included in the model. Finally, when the transmission firm is maximizing welfare and is subject to a budget constraint, then this constraint creates a link between the different time periods. Note that, if the network operator is a profit maximiser, then there is no (binding) budget constraint.

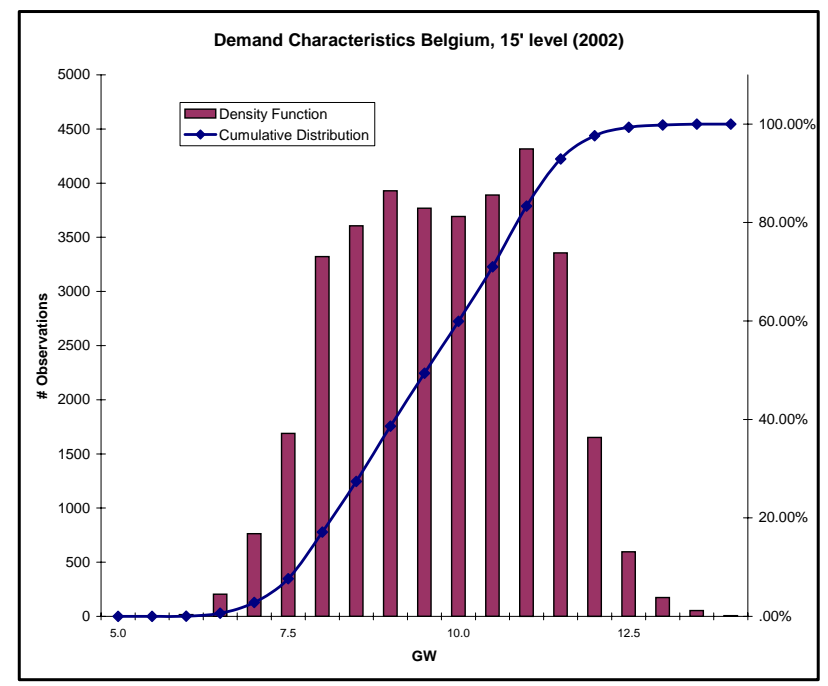

Figure 2: Histogram of electricity demand in Belgium in 2002 (Source Elia).

\footnotetext{
22 The network of one part of Luxembourg forms an integral part of the Belgian network. Demand levels for that part are included in the model.
} 


\subsection{Network operator}

The network operator's total costs sum up to $€ 649$ million in $2002^{23}$. Capital costs are about $50 \%$ of total costs, the remaining $50 \%$ being operating costs, such as wages and network maintenance costs. Wages and network maintenance costs are not directly related to the amount of MW transported over a line, they are inherent to the existence of that line. Therefore, as more detailed data on the cost structure of the network operator is lacking, we assume all costs to be fixed.

Network losses are neglected in the model. Clearly, these would depend on the actual use of the network. With a total electricity demand of $83.4 \mathrm{TWh}$ in 2002, the network operator's average cost is $€ 7.78$ per MWh.

\subsection{Calibration}

Electricity prices in Belgium are relatively high, but not excessively high compared to end-user prices in the neighbouring countries. In our opinion, current Belgian electricity prices do not reflect the market power that Electrabel potentially has in the Belgian market. At least two arguments can be put forward to explain this short run pricing behaviour.

First, Electrabel signed long term contracts with a large number of its customers. As a result, the firm will be less inclined to drive up prices in the Belgian market as a larger fraction of his sales are already sold at a contracted price. In this way the company forgoes some short run profits, but it locks-in a long-run profit. By selling in the long run, the monopolist deters entry, thereby leaving less room for competitors.

Second, we believe that there might be a political threshold against increasing electricity prices too much. Increasing electricity prices too much could trigger an intervention by Belgian politicians, leading to, for example, a divesture of Electrabel's assets, or the virtual auctioning of production capacity.

For these reasons, we think that electricity prices in Belgium are somewhere in between the competitive prices and the short run monopoly prices. This conjecture will be used to calibrate the model, as will be explained in the next paragraphs. The calibration of the model involves three steps.

\section{Fixing periodic aggregate demand and the length of each period}

The first step is to decide about the level of electricity demand in each of the four periods, and about the length of each period in a standard year. This has been done on the basis of the data presented in Figure 2. This figure shows how often a certain demand level occurs in the Belgian market. We will consider 4 periods with average demand levels fixed at $8,10,11.5$ and $12.5 \mathrm{GW}$. The length of each period is then set such that the cumulative distribution function of the 4 periods approximates the observed cumulative distribution function (Table 3). As $500 \mathrm{MW}$ of this demand is provided by small generators, the demand level as seen by the generators in our model is fixed $500 \mathrm{MW}$ lower. Thus, the reference quantities used to calibrate the demand functions are $7.5,9.5,11$ and $12 \mathrm{GW}$.

23 Taken from the Annual report of ELIA (2002). 


\begin{tabular}{cccccc}
\hline Period & $\begin{array}{c}\text { Observed } \\
\text { Demand } \\
(\mathrm{GW})\end{array}$ & \multicolumn{2}{c}{ Period Length } & Model Demand & $\begin{array}{c}\text { Reference } \\
\text { price }\end{array}$ \\
\hline $\mathbf{1}$ & 12.5 & 208 & $2.4 \%$ & 12.0 & 52.7 \\
$\mathbf{2}$ & 11.5 & 1759 & $20.1 \%$ & 11.0 & 45.4 \\
$\mathbf{3}$ & 10.0 & 3410 & $38.9 \%$ & 9.5 & 43.1 \\
$\mathbf{4}$ & 8.0 & 3383 & $38.6 \%$ & 7.5 & 34.5 \\
\hline
\end{tabular}

Table 3: Calibration for the 4 time periods

\section{Fixing a reference price for each period}

Given the periodic electricity demand as it is derived in the first step, we minimize the production costs to supply this demand. Here, it is assumed that pumped water storage can only be used in the periods one and two. In the periods three and four, pumped storage plants pump water into a reservoir. Via this procedure, we obtain the marginal production cost for each period.

In each period, we assume the reference price $p_{t}^{\text {ref }}$ to be equal to the sum of this system marginal production cost $M C_{t}^{\text {system }}$, a fixed mark-up for the generators $\Delta$, and the average transmission price $T$.

$$
p_{t}^{\text {ref }}=M C_{t}^{\text {system }}\left(q_{t}^{\text {system }}\right)+\Delta+T
$$

The average cost of the network operator is $€ 7.78$ per MWh. The mark-up of the generators is assumed to be $€ 7.5$ per MWh.

\section{Fixing periodic electricity demand in the consumption nodes}

In the third step, we derive for each node a linear demand function. The price elasticity of demand is assumed to be -0.2 in all nodes and all periods. Total demand is distributed proportionally over the different periods on the basis of the demand data in Van Roy (2001) and the reference prices are calculated in step 2. This information is sufficient to derive for each consumption node the parameters of the linear demand function.

\section{SIMULATION RESULTS}

This section discusses simulation results that look at the impact of different ownership structures on the market outcome, both in terms of the aggregate welfare level and individual profits. The simulations presented in this paper serve the purpose of illustrating these outcomes.

By different ownership structures we mean active or passive ownership, as discussed in section 2.3 of the paper. With passive ownership, the incumbent collects a share $\rho$ of the transmission firm's profit. With active ownership, he will also be able to influence the decision process of the transmission firm. Active ownership is measured by the parameter $\omega$. With $\omega=0$, we have no active ownership, i.e. the incumbent has no bargaining power in the transmission firm. With $\omega>0$, we have active ownership, i.e. the incumbent has bargaining power in the transmission firm. Figure 3 summarises the parameter combinations that are assumed in the numerical simulations. 
Both parameters $\omega$ and $\rho$ show up in the objective function of the network operator. Thus, the network operator's behaviour depends on both parameters. The objective function of the generators only depends on the ownership share $\rho$ but not on the bargaining power $\omega$.

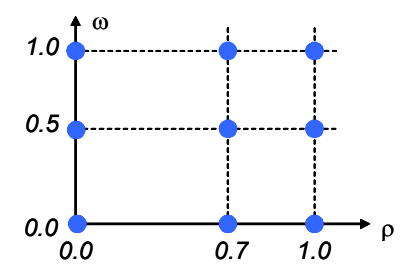

Figure 3: Combinations of $\rho$ and $\omega$.

All firms, in transmission as well as in generation, are assumed to maximise profit. The subsections 5.2 and 5.3 assume monopoly and Cournot behaviour in the generation market, respectively. First, in subsection 5.1, we discuss two benchmark scenarios.

\subsection{Two benchmark scenarios}

In this subsection, we discuss two benchmark scenarios, one with a welfare maximising transmission firm, and one with a profit maximising transmission firm. Both scenarios assume perfect competition in generation, and unbundled generation and transmission activities, i.e. $\rho=\omega=0$.

Column 1 in Table 4 presents the 'second best' scenario. It gives the highest level of welfare one can obtain, taking into account that the transmission firm is subject to a budget constraint. The budget constraint obliges the network operator to set prices above marginal cost. ${ }^{24}$ This scenario can also be interpreted as the case where the network operator is efficiently regulated, and where the generation market is perfectly competitive.

Scenario 2 is also featured by perfect competition in generation, but now regulation is inefficient or inexistent. Instead the network operator is maximizing his profit. As expected, a comparison of both scenarios reveals a gain that can be achieved (given a perfectly competitive generation market) by improving the regulation of the transmission firm.

The following two subsections discuss a profit maximising transmission firm, with a monopolist (scenario 3-11) and an oligopoly in generation (scenario 12-20).

\subsection{A monopoly in the generation market}

Figure 4 presents welfare measures for each of the 9 parameter combinations. Each block is a measure of welfare corresponding to a given combination of $\rho$ and $\omega$. Total welfare is the sum of three components: the consumer surplus, measured downwards, the transmission firm's producer surplus and the generator's producer surplus. Producer surpluses are measured upwards. The discussion of the results is focussed on the changes of the block sizes.

\footnotetext{
${ }^{24}$ Due to increasing returns to scale in transmission, the budget constraint would not hold, if the network operator prices at marginal costs. We refer to Pepermans and Willems (2004) for a discussion of the case of a welfare maximising network operator under different assumptions with respect to the operation of the generation market.
} 


\section{Changing in the ownership share $(\rho)$}

First, consider changes in $\rho$ while keeping $\omega$ constant. In Figure 4, this corresponds to changes in block sizes in the horizontal dimension.

\section{Welfare}

The simulation results reveal that a changing ownership share $\rho$, has no impact on the market outcome in terms of aggregate welfare and consumers' surplus ${ }^{25}$. For lower levels of bargaining power ( $\omega=0$ and $\omega=0.5$ ), welfare is exactly the same, (compare the scenarios 6-7 and 9-10 in Table 4), while for higher levels of bargaining power (the scenarios 5,8 and 11) welfare is slightly different due to the presence of a binding budget constraint for the transmission firm.

\section{Distribution of profits}

The distribution of profits between the generator and the network operator is affected by changes in cross ownership. A higher ownership share $\rho$ increases the consolidated profits of the transmission firm, and decreases the consolidate profits of the incumbent generator. This can be seen in Figure 4 and checked in Table 4 by comparing the simulation results $(3,6,9),(4,7,10)$, and $(5,8,11){ }^{26}$.

How can this be explained? Three effects play a role: (1) The incumbent receives a fraction $\rho$ of the transmission firm's profit. For each unit produced and sold, the generator pays the transmission price $\left(\tau_{i}^{p}+\tau_{j}^{c}\right)$ to the network operator, of which $\rho\left(\tau_{i}^{p}+\tau_{j}^{c}\right)$ is recovered via the profit share. Thus, the net transmission cost to the incumbent of producing and selling one unit of output is $(1-\rho)\left(\tau_{i}^{p}+\tau_{j}^{c}\right)$. The incumbent pays less than the full price. (2) A higher ownership share $\rho$, lowers the price elasticity of the demand for transmission, which induces the profit maximising network operator to charge higher transmission prices (the inverse elasticity rule). These first two effects cancel out, such that there is no net effect. (3) When the incumbent owns part of the transmission firm, he also owns a share $\rho$ of the fixed costs of the network operator. The third effect lowers the profit of the incumbent and increases the transmission firms' profit as $\rho$ increases.

Because this latter effect is related to the distribution of the fixed cost, which cannot be influenced by the behaviour of the players, there is no impact on the overall welfare level. The first two effects induce behavioural reactions, but the resulting welfare effects exactly cancel out.

\section{Changing in the bargaining power $(\omega)$}

Now, consider changes in the bargaining power. In terms of Figure 4, these are changes in the vertical dimension.

For any value of $\rho$ we find that increased bargaining power results in higher welfare levels. The reason for this is the elimination of double marginalisation.

For example, with $\rho=\omega=0$ (scenario 3 in Table 4 and the lower left block in Figure 4), we have two monopolies, both charging a monopoly price without taking into account the external effect they cause on each other by doing so. As the bargaining power $(\omega)$ increases, these external effects are

\footnotetext{
${ }^{25}$ With $\rho=1$ we have indeterminacy in the numerical problem. The reason is that the first order conditions for the incumbent do no longer depend on transmission prices, which implies that there might be a problem in making sure that there is no congestion on the network. For that reason, the model was solved for $\rho=0.99$.

${ }^{26}$ It can be shown that this result holds under general demand conditions and with constant marginal costs of transmission.
} 
(partially) internalised by the transmission firm. This reduces equilibrium market prices and increases welfare $^{27}$. With $\omega=1$, we have a complete internalisation of the external effect and the outcome converges to the case with a monopolist in the generation market that has full control over the pricing behaviour of the transmission firm. Increasing $\omega$ thus results in higher consolidated profits for the incumbent generator, which is in line with expectations.

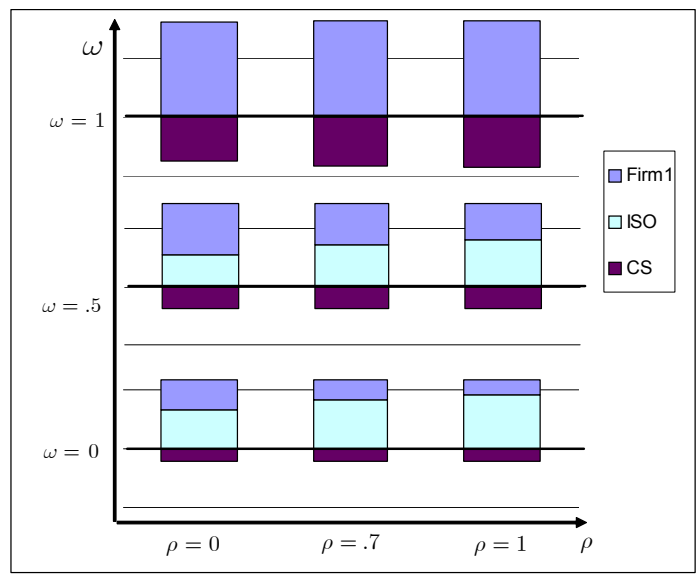

Figure 4: Effect of $\rho$ and $\omega$ on welfare with a monopoly in the generation market.

${ }^{27}$ Even without owning a share of the transmission firm $(\rho=0)$, the incumbent might still have some bargaining power in the transmission firm. This could for example result from historical ties that existed before the liberalisation process. Simulations 3 to 5 look for different levels of bargaining power $\omega$, 

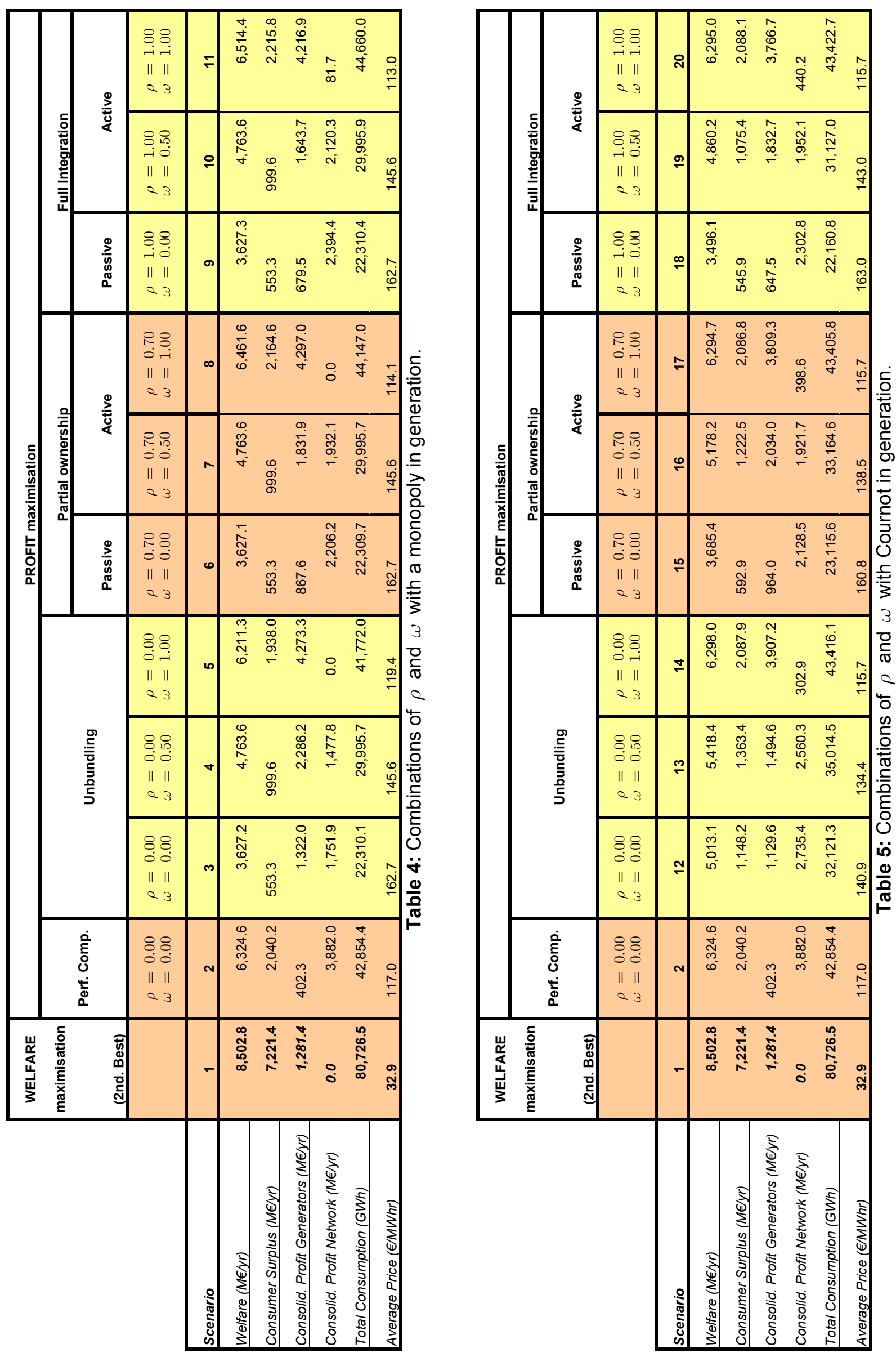


\subsection{Cournot players in the generation market}

Having more than one generator complicates a straightforward interpretation of the simulation results. These results can be found in Table 5, a graphical presentation of the welfare effects is given in Figure 5. Again, we start with a discussion of the results for changing values of $\rho$, while keeping $\omega$ fixed. In a next step, we change $\omega$ and keep $\rho$ constant.

\section{Changing the ownership share $(\rho)$}

\section{Welfare}

Contrary to the monopoly case, the ownership share $\rho$ does matter for the level of welfare with Cournot. Again, the three effects mentioned in the monopoly case play a role. However, now the first two effects do create welfare effects because of the asymmetric impact of $\rho$ on the generation firms. With larger values of $\rho$, the profit maximising transmission firm still has an incentive to charge higher prices to the incumbent. A higher $\rho$ implies less elastic demand for transmission services by the incumbent and thus a larger potential for increased profits from price increases. The incumbent does not bother, because the higher value of $\rho$ also implies a higher profit share for the incumbent.

However, the transmission firm now also has an incentive to charge higher prices to the entrants because this will reduce the demand for transmission services by the entrants and increase the demand for transmission services by the incumbent. Here the cross-price elasticity of the demand for transmission plays a crucial role, and it is assumed that electricity produced by entrants is a substitute for electricity produced by the incumbent (positive cross-price elasticity). Now, a welfare loss is created because the behavioural effects do not net out. Note that this effect will occur for any value of $\omega$.

With positive values of $\omega$, an additional effect comes into play because the transmission firm takes into account the profits of the incumbent. This will further induce the transmission firm to set transmission prices such that entrants are priced out of the market, leaving a de facto generation monopoly for the incumbent.

With the simulation results presented in this paper, it cannot be checked what the impact is on welfare of alternative ownership structures in the generation market, i.e. to what extent the results depend on who owns the low marginal cost plants. In the current simulations the incumbent owns the low cost (nuclear) plants.

\section{Distribution of profits}

Table 5 shows that reducing the ownership share $\rho$, with $\omega=0$ (i.e. passive ownership), increases the global profits captured by the generation sector. With $\omega=0.5$, profits will initially increase and then fall as generation and transmission are unbundled. With $\omega=1.00$, reducing the ownership stake results in an unambiguous increase in profits for the generation sector as a whole.

Table 6 takes a more detailed look into the profit sharing between the generation firms and the network operator. Allowing the incumbent to have an increasing financial stake in the transmission firm initially results in significantly higher consolidated profits for the incumbent if $\omega$ is small. This result is driven by the first two effects described above. For values of $\rho$ approaching 1 , the incumbent's profit is reduced, due to the fixed cost effect. 
For larger values of $\omega$, an increasing ownership share has a negative effect in all simulations (see Table 6, scenarios 14, 17 and 20). The transmission firm takes into account the stakes of the incumbent generator anyway. This results in a pricing strategy that reduces the market share of the entrants. Increasing $\rho$ then mainly has as an effect that the incumbent owns a larger share of the network operator's fixed cost.

The effect of the ownership share on the network operator's consolidated profit depends the bargaining power $\omega$. With passive ownership $(\omega=0)$, its profit first decreases for small values of $\rho$ and then increases for larger values of $\rho$. With active ownership $(\omega=.5,1)$, profit always increases with the ownership share $\rho$.

\section{Incentives for entry in generation}

The consolidated profits for the generators that have no stake in the transmission firm decrease with the ownership share $\rho$ due to the reasons explained before. This leads us to an important conclusion with respect to entry of new generation firms: Possible entrants will only enter the generation sector when they can cover their fixed costs. The results show that the incentives for entry are highest if the generation market is unbundled and much smaller when the incumbent has a financial stake in the transmission firm. The results in Table 6 also suggest that reducing the ownership share $(\rho)$ without at the same time reducing the bargaining power of the incumbent $(\omega)$ would not contribute very much to the profits of the entrants and thus their incentives to enter. Furthermore, reducing the bargaining power with an unchanged ownership share could even reduce incentives for entry. This can be seen by comparing the scenarios 20,19 and 18 or 16 and 15 . This strongly suggests that the ownership share as well as the bargaining power should be reduced in order create proper incentives for entry in generation.

\section{Changing the bargaining power $\omega$}

\section{Welfare}

The effect of increasing values of $\omega$ with constant $\rho$ can be seen in Table 5 and in Figure 5 (the vertical dimension). For a Cournot generation market with unbundling (scenarios 12-14), partial ownership (scenarios 15-17) and full integration (scenarios 18-20), we find that bargaining power increases welfare. Again, the double marginalisation intuition is at the basis of this result.

\section{Distribution of profits}

Table 6 takes a more detailed look into the profit sharing between the Cournot players and the network operator. Increased bargaining power $(\omega)$ results in higher consolidated profits for the incumbent and lower for the transmission network operator. The transmission firm will use transmission prices to force entrants out of the market, which will result in an increased market share and thus a higher profit for the incumbent. 


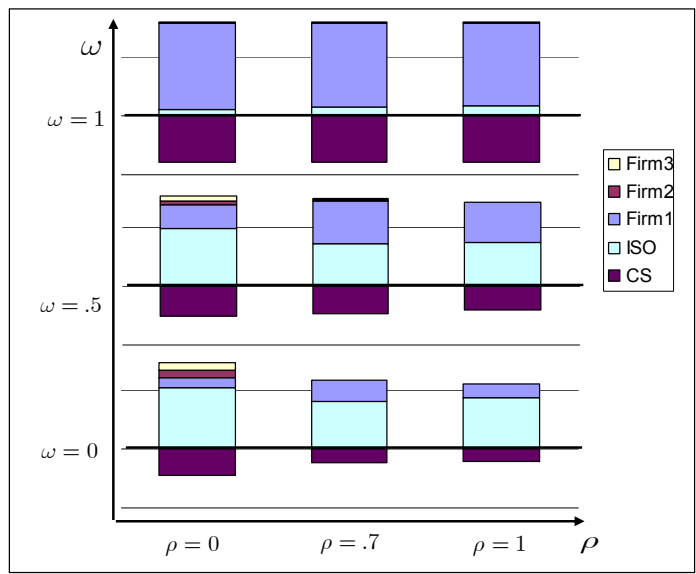

Figure 5: Effect of $\rho$ and $\omega$ on welfare with Cournot players in the generation market.

\begin{tabular}{|c|c|c|c|c|c|c|c|c|c|}
\hline & \multirow{2}{*}{\multicolumn{3}{|c|}{ Unbundling }} & \multicolumn{3}{|c|}{ Partial ownership } & \multicolumn{3}{|c|}{ Full Integration } \\
\hline & & & & \multirow{2}{*}{$\begin{array}{c}\text { Passive } \\
\begin{array}{l}\rho=0.70 \\
\omega=0.00\end{array}\end{array}$} & \multicolumn{2}{|c|}{ Active } & \multirow{2}{*}{$\begin{array}{c}\text { Passive } \\
\begin{array}{l}\rho=1.00 \\
\omega=0.00\end{array}\end{array}$} & \multicolumn{2}{|c|}{ Active } \\
\hline & $\begin{array}{l}\rho=0.00 \\
\omega=0.00\end{array}$ & $\begin{array}{l}\rho=0.00 \\
\omega=0.50\end{array}$ & $\begin{array}{l}\rho=0.00 \\
\omega=1.00\end{array}$ & & $\begin{array}{l}\rho=0.70 \\
\omega=0.50\end{array}$ & $\begin{array}{l}\rho=0.70 \\
\omega=1.00\end{array}$ & & $\begin{array}{l}\rho=1.00 \\
\omega=0.50\end{array}$ & $\begin{aligned} \rho & =1.00 \\
\omega & =1.00\end{aligned}$ \\
\hline & 12 & 13 & 14 & 15 & 16 & 17 & 18 & 19 & 20 \\
\hline Firm 1 (incumbent) & 55,358 & $121,891.6$ & $438,150.4$ & 108,416 & 213,835 & $427,242.3$ & $73,768.5$ & 203,980 & $422,502.6$ \\
\hline Firm 2 & 37,121 & $24,692.3$ & $4,101.6$ & 869 & 9,410 & $3,965.2$ & 75.8 & 2,713 & $3,908.3$ \\
\hline Firm 3 & 36,466 & $24,037.4$ & $3,773.5$ & 766 & 8,946 & $3,642.2$ & 67.2 & 2,522 & $3,580.2$ \\
\hline Network Operator & 312,256 & $292,271.6$ & $34,580.1$ & 242,974 & 219,367 & $45,506.7$ & $262,874.8$ & 222,841 & $50,246.6$ \\
\hline
\end{tabular}

Table 6: Consolidated profit ( $€$ per hour) and ownership structures under Cournot.

\subsection{Monopoly versus Cournot versus perfect competition}

\section{Increasing competition in generation}

This section discusses the effect of increased competition in generation keeping the ownership share, the bargaining power, and the set of generation plants constant. ${ }^{28}$

With unbundling in generation and transmission and in the absence of bargaining power ( $\rho=\omega=0)$, we have the unambiguous result that more competition in generation results in increased welfare. This can be seen by comparing the scenarios 3,12 and 2. Reducing market power (moving from 3 over 12 to 2) results in lower generation prices, increased demand and thus higher welfare. This increase in welfare is shared among the consumers and the transmission firm. Note that scenario 2 assumes profit maximising by the transmission firm, which results in monopoly pricing for transmission. As explained before, improving the regulation of the transmission firm, i.e. moving from scenario 2 to scenario 1 will further increase welfare, because now the monopoly behaviour of the transmission firm is put to an end.

With other combinations of $\rho$ and $\omega$, the results are more ambiguous, but in most cases Cournot does better than monopoly in terms of welfare. Three effects contribute to the welfare outcome. First, more competition is beneficial as it reduces the margin in the generation market. Second, as

\footnotetext{
${ }^{28}$ Increased competition could also change the set of generation plants. Entry could increase the number of generation plants.
} 
discussed before, bundling generation and transmission is beneficial as it reduces the total margin (the double marginalisation effect). However, with Cournot competition, non-incumbent generation firms will not contribute to this second effect because they have no bargaining power in the transmission firm. Third, larger values for $\rho$ and $\omega$ induce the network operator to favour the incumbent, which will result in a non-optimal use of the available generation capacity. Cheaper generation capacity owned by entrants will not be used and will be replaced by more expensive plants owned by the incumbent.

Overall, these three effects sum to a positive welfare effect when the number of players increases. Only in the special case where $\omega=1.00$, a monopoly outperforms a Cournot market in welfare terms, a result which is determined by the dominance of the second (increased double marginalisation) effect.

\section{Comparing the limiting cases}

One integrated monopolist, controlling generation as well as transmission (scenario 11), is better than a monopoly in transmission and perfect competition in generation (scenario 2). This result is driven by the fact that, in the latter case, the network operator wants to extract inframarginal rents from the competitive generators, i.e. monopsony behaviour by the network operator. This creates extra deadweight loss. With generation and transmission joined in one firm, there is no reason to extract this rent.

\subsection{Vertical integration: should it be more or less?}

The main messages can be summarised as follows:

- The simulations show that unbundling generation and transmission should be done with care. With insufficient competition in generation and/or imperfect regulation of transmission, unbundling can results in welfare losses.

- Reducing the incumbent's ownership share increases welfare and has positive, but relatively small, effects on the incentives for entry.

- Reducing the incumbents' bargaining power decreases welfare. Furthermore, it also gives relatively weak incentives for entry.

- Cutting the incumbent's ownership share and his bargaining power simultaneously will reduce welfare, but gives the best incentives for entry in generation.

These observations suggest that the fastest road towards a more efficient electricity market is a road that implies a welfare reduction at an intermediate stage. The best way to stimulate entry in generation is unbundling of generation and transmission, both in terms of ownership and bargaining power. In the 'short run', this reduces welfare, due to the creation of the double marginalisation problem, but, at the same time, it also creates better incentives for new generation firms to enter the market. This latter effect is due to fact that the incentives for asymmetric pricing by the network operator are reduced.

\section{CONCLUSIONS}

The purpose of this paper is to look at the impact of unbundling, possibly partially, of generation and transmission activities in the electricity sector. Given a situation with imperfect competition in generation or imperfect regulation of the network operator, it is not clear whether unbundling will result in a better outcome in terms of efficiency and welfare than in the initial situation, with vertically integrated firms. 
We construct a numerical model that explicitly considers partial unbundling and the competitive structure in generation. Essentially, we assume varying degrees ownership unbundling of generation and transmission, while still allowing for some degree of interaction between the firms. Generation firms are (partial) owners of the transmission firm, which allows them to capture some of the profits of the latter. This ownership can either be passive or active, depending on what is assumed about the generators' ability to influence the transmission firm's decision process. Ownership is said to be passive, when the generation firm cashes a part of the transmission firm's profit without having a direct impact on the decision process of the latter. Ownership is of an active nature, if the generator has a direct influence on the transmission firm's decision process.

We assume consumers to be price takers in the electricity market. Generators are Cournot players in production and sales, but they are price takers in the transmission market. The network operator is a Stackelberg leader and sets the transmission price before the generators decide about their production and sales.

The parameterisation of the model is inspired by the technical characteristics of the Belgian electricity system. It includes the Belgian high voltage transmission grid, and the most important lines in France and the Netherlands. The network is presented as a linearised DC-load flow model. Transmission is limited by the thermal constraints of the lines and $n-1$ security constraints are imposed. If one of the lines breaks down, then the remaining lines should be able to transport the electricity.

Apart from two benchmark scenarios, two alternative scenarios are developed for the generation market. The first scenario assumes a monopoly in generation, while the second one considers a Cournot generation market. In each of the last two scenarios, different cases of passive and active ownership are simulated.

The simulations show that unbundling generation and transmission should be done with care. First, reducing the incumbent's ownership share while keeping the bargaining power constant will not reduce welfare, but in terms of incentives for entry, the effects will be relatively small. Second, decreasing the incumbents' bargaining power with constant ownership will decrease welfare and reduce the incentives for entry. Finally, cutting the incumbent's ownership share and his bargaining power simultaneously will reduce welfare, but gives the best incentives for entry in generation.

These observations suggest that the fastest road towards a more efficient electricity market is a road that implies a welfare reduction at an intermediate stage. The best way to stimulate entry in generation is unbundling of generation and transmission, both in terms of ownership and bargaining power. In the 'short run', this reduces welfare, but at the same time it also creates better incentives for new generation firms to enter the market. 


\section{REFERENCES}

BOLLE, F., (1992), Supply function equilibria and the danger of tacit collusion: the case of spot markets for electricity, Energy Economics, vol. 14, nr. 2, p. 94-102.

BORENSTEIN, S. and BUSHNELL, J. B., (1999), An empirical analysis of the potential for market power in California's Electricity Industry, Journal of industrial economics, vol. 47, nr. 3, p. 285323.

BORENSTEIN, S., BUSHNELL, J. B., and STOFT, S. E., (1998), The competitive effects of transmission capacity in a deregulated electricity industry, Rand Journal of Economics, vol. 31 , nr. 2, p. 294-325.

BORENSTEIN, S., BUSHNELL, J., and KNITTEL, C. R. , (1999), Market Power in Electricity Markets: Beyond Concentration Measures., Energy Journal, vol. 20, nr. 4, p. 65-88.

BRESNAHAN, T. F. en SALOP, S. C., (1986), Quantifying the competitive effects of production joint ventures, International Journal of Industrial Organization, vol. 4, nr. 2, p. 155-175.

CARDELL, J. B., HITT, C. C., and HOGAN, W. W., (1997), Market power and strategic interaction in electricity networks, Resource and Energy Economics, vol. 19, nr. 1-2, p. 109-137.

DAY, J. D., HOBBS, B. F., and PANG, J.-S., (2002), Oligopolistic Competition in Power Networks: A Conjectured Supply Function Approach, Mimeo, p. 10.

EUROPEAN COMMISSION, (2004), Third benchmarking report on the implementation of the internal electricity and gas market, Brussels, p. 44.

GREEN, R., (1996), Increasing competition in the Brittisch Electricity Spot Market, Journal of industrial economics, vol. 44, nr. 2, p. 205-216.

GREEN, R. J. and NEWBERY, D. M., (1992), Competition in the British Electricity Spot Market, Journal of Political Economy, vol. 100, nr. 5, p. 929-953.

HOBBS, B. F., (2001), Linear Complementarity Models of Nash-Cournot Competition in Bilateral and POOLCO Power, IEEE Transactions and Power, vol. 16, nr. 2, p. 194-202.

HOGAN, W. W., (1997), A market power model with strategic interaction in electricity networks, Energy Journal, vol. 18, nr. 4, p. 107-141.

KLEMPERER, P. and MEYER, M., (1989), Supply function Equilibria in Oligopoly under uncertainty, Econometrica, vol. 57, nr. 6, p. 1243-1277.

NEWBERY, D. M., (1998), Competition, contracts, and entry in the electricity spot market, Rand Journal of Economics, vol. 29, nr. 4, p. 726-749.

OREN, S. S., (1997), Economic Inefficiency of Passive Transmission Rights in Congested Electricity Systems with Competitive Generation, The Energy Journal, vol. 18, nr. 1, p. 63-83. 
PEPERMANS, G. en WILLEMS, B., (2004), Ramsey Pricing in a Congested Network with Market Power in Generation: A Numerical Illustration for Belgium, ETE-Working paper, Leuven, p. 36.

RUDKEVICH, A., DUCKWORTH, M., and ROSEN, R., (1998), Modeling Electricity Pricing in a Deregulated Generation Industry: The Potential for Oligopoly Pricing in a Poolco, The Energy Journal, vol. 19, nr. 3, p. 19-48.

SMEERS, Y. and WEI, J.-Y., (1997), Spatially Oligopolistic Model with Opportunity Cost Pricing for Transmission Capacity reservations - A Variational Approach, 9717, Louvain-La-Neuve, p. 26.

STOFT, S. E., (1997), The effect of the transmission grid on market power, mimeo, Berkley.

TIROLE, J., (1988), The Theory of Industrial Organisation, The MIT Press, Cambridge (Mass.), p. 479.

VAN ROY, P., (2001), Study of the technical-economical aspects of the liberalisation of the electricity sector, K.U.Leuven, Leuven, p. 203.

VON DER FEHR, N. and HARBORD, D., (1993), Spot Market Competition in the UK Electricity Industry, The Economic Journal, vol. 103, p. 531-546.

WEI, J.-Y. and SMEERS, Y., (1999), Spatial Oligopolistic electricity models with Cournot generators and regulated transmission prices, Operations Research, vol. 47, nr. 1, p. 102-112.

WILLEMS, B., (2002), Modeling Cournot Competition in an Electricity Market with Transmission Constraints, Energy Journal, vol. 23, nr. 3, p. 95-125.

WOLAK, F. A. and PATRICK, R., (2001), The impact of Market Rules and Market Structure on the Price Determination Process in England and Wales Electricity Market, NBER Working Paper 8248, Stanford, p. 88.

WOLFRAM, C. D., (1998), Strategic bidding in a multiunit auction: an empirical analysis of bids to supply electricity in England and Wales, Rand Journal of Economics, vol. 29, nr. 4, p. 703725. 
The Center for Economic Studies (CES) is the research division of the Department of Economics of the Katholieke Universiteit Leuven. The CES research department employs some 100 people. The division Energy, Transport \& Environment (ETE) currently consists of about 15 full time researchers. The general aim of ETE is to apply state of the art economic theory to current policy issues at the Flemish, Belgian and European level. An important asset of ETE is its extensive portfolio of numerical partial and general equilibrium models for the assessment of transport, energy and environmental policies.

\section{ETE WORKING PAPER SERIES 2005}

N²005-01

Pepermans G., Willems B. (2005), The potential impact of crossownership in transmission: An application to the Belgian electricity market

\section{ETE WORKING PAPER SERIES 2004}

$N^{\circ} 2004-16$

$N^{\circ} 2004-15$

$N^{\circ} 2004-14$

$N^{\circ} 2004-13$

No2004-12

$N^{\circ} 2004-11$

$N^{\circ} 2004-10$

No2004-09

$N^{\circ} 2004-08$

N²004-07

N²004-06
Franckx L, D'Amato A., Brose I. (2004), Multi Pollutant Yardstick Schemes as Environmental Policy Tools

Rousseau S., Proost S. (2004), The Relative Efficiency of Marketbased Environmental Policy Instruments with Imperfect Compliance

Eyckmans J., Finus M. (2004), An Almost Ideal Sharing Scheme for Coalition Games with Externalities

De Borger B., Mayeres I. (2004), Taxation of car ownership, car use and public transport: insights derived from a discrete choice numerical optimisation model

De Borger B., Proost S. (2004), Vertical and horizontal tax competition in the transport sector

de Palma A., Dunkerley F., Proost S. (2004), Imperfect Competition and Congestion in a City with asymmetric subcenters

Calthrop E., Proost S. (2004), Regulating on-street parking

de Palma A., Proost S. (2004) Imperfect competition and congestion in the City

Pepermans G., Willems B. (2004), Ramsey Pricing in a Congested Network with Market Power in Generation: A Numerical Illustration for Belgium

Delhaye E. (2004), Traffic safety: speed limits, strict liability and a km tax

Eyckmans J., Finus M. (2004), An Empirical Assessment of Measures to Enhance the Success of Global Climate Treaties 